\title{
Enterprise Management Innovation in the Informationalized Consumption Mode
}

\author{
Jingyan Wang, Zhen Zhu \\ Foshan University, Foshan, China \\ wangjy@fosu.edu.cn
}

\begin{abstract}
With rapid development of computer technology and communication technology, the application of information technology has penetrated into all social and economic fields. The focus of enterprise competition has turned to speed competition, information competition and knowledge competition. In order to have advantages in market competition, this paper proposes some suggestions about enterprise management innovation in the informationalized consumption mode. These suggestions include making development strategy by use of competitive intelligence, motivating creative power via netizen evaluation collection, changing operation mode through the application of information technology, deciding product development by means of market demand mining, and bringing products to market with the help of network marketing.
\end{abstract}

Keywords- competitive intelligence; operation mode; consumer evaluation; demand mining; network marketing

\section{INTRODUCTION}

With the growing popularity of Internet application and the rapid development of mobile communication technology, people can conveniently use desktop PC or mobile terminal to access Internet for getting information. So people's information need and knowledge desire are satisfied, and their cognitive ability and knowledge level is greatly improved. Such specific behavior mode is gradually formed and also brought influence on people's daily consumption habit. For example, before buying a commodity, people will habitually use network to collect information about similar types of commodities, and then put into consumption action via comparative analysis.

At present, the application of information technology has penetrated into all social and economic fields; a fundamental change has taken place in enterprise's survival and competitive environment. The focus of market competition has turned to speed competition, information competition and knowledge competition. And competition range also changed from regional to global [1]. Therefore, all enterprises must make business innovation in order to meet consumer demand, to win the advantage in fierce market competition. From the fusion of informatization and industrialization, this paper proposes some suggestions about enterprise management innovation in the informationalized consumption mode.

\section{INFORMATIONALIZED CONSUMPTION MODE}

In the information society, information technology supports people's production, living and entertainment every hour and moment. Consumers would more or less, actively or passively use information technology to assist the implementation of daily consumption, and such consumption mode has gradually become people's consumption habits.

Consumers have the desire for consumption on internal demand and external stimulus; and external stimulus come from product marketing information on traditional media or network media. In the entire consumption life cycle, consumers may use such wireless terminal as hand-phone, PDA, notebook computer, etc or desktop PC terminal, to access network through wired or wireless mode for information collecting, message communicating and online evaluating. After the completion of evaluation and selection, purchase behavior may implement through traditional channels (for example: entity stores) or network channels (for example: online shopping). In the last stage of consumption life cycle, consumers can get treatment advice from net-friends, or complete post treatment of product through mutual exchange or online auction. It was clear that, in consumption life cycle, although reference guide of social network and knowledge experience still play an important role, but the impact of Internet generated more and more can not be ignored.

In today's digital age, Internet already created a new disseminating and marketing ecological environment which is very different with traditional media. Communication and free talk can be realized with each other between consumers and friends, between consumers and manufacturers. The changes of propagation environment and consumer behavior lead to the change of consumer decision-making process; consumption trajectory also changed from one-way progressive pattern to SICAS (Sense-Interest \& Interactive-Connect \& CommunicateAction-Share) multi-dimensional interaction pattern, as shown in Figure 1 [2].

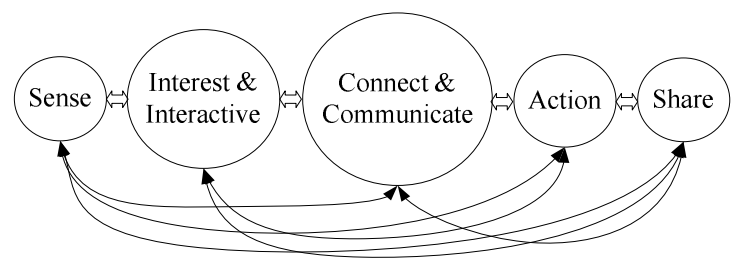

\section{FIGURE1.SICAS MULTI-DIMENSIONAL INTERACTION PATTERN}

In the informationalized consumption mode, such network communication platform as instant communication tool, search engine, forum, blog/personal space, micro-blog and virtual community could be used by consumers for apperceiving and 
communicating among consumers, between consumers and manufacturers. And then consumers take action to buy, share experience mutually. This process can carry out every hour and moment, whenever and wherever possible. And in such new consumption mode, free or not-free information consumption always happens.

\section{ENTERPRISES MANAGEMENT INNOVATION}

\section{A. Making Development Strategy by Use of Competitive Intelligence}

Competitive intelligence (CI) emerges as the times required in the background of global economic integration, information resources explosion and market competition fierce, it is about the information and research of competitive environment, competitors and competitive strategy. The role of competitive intelligence in enterprise development can be summarized as follows: (1) Early warning about opportunities and risks; (2) Monitoring and appraising of competitors; (3) Monitoring and analyzing of competitive environment; (4) Tracking of new technology and innovation; (5) Establishing differentiated marketing strategies; (6) Supporting enterprise management decision. Obviously, competitive intelligence can play a crucial role in enterprises survival and enterprises development, and more and more enterprises begin gradually to attach importance to competitive intelligence work.

When small and medium enterprises introduce competitive intelligence, they should utilize competitive intelligence to assist decision-making, but not to increase enterprise burden. Based on own human resources, financial strength and information technology infrastructure, enterprises may set up working network of competitive intelligence by combination of full-time working manner and part-time working manner [3]. Part-timers of competitive intelligence are employed in each department, they may regularly or irregularly send analysis report of competitive intelligence collected to full-time personnel (professionals of competitive intelligence), so the competitive intelligence system throughout every corner of enterprise is formed, as shown in Figure 2.

Decision makers of small and medium enterprises must establish the concept of information being resources and information being wealth. They should set competitive intelligence in the strategic position, and personally involved in intelligence analysis work. Training staff's consciousness of competitive intelligence, the active atmosphere of competitive intelligence is built within enterprise.

Competitive intelligence collection can be carried out by three methods. First method is collected from newspaper, magazine, patent, business directory, guild publication, government report, technical standard, yearbook, etc. Second method is collected from various meeting of investment, exhibition, fraternity, academic conference, procurement conference, news release conference, new products demonstration, new technology demonstration, etc. Third method is colleted with the help of advisory services, colleges and universities, business database and other external resources.

In conclusion, after an effective competitive intelligence system is established in small and medium enterprises, all strategic decisions (including development strategy, R \& D strategy, marketing strategy, financial strategy, production strategy, etc.) will be supported by objective information, making decision more scientific, effectiveness and pertinence.

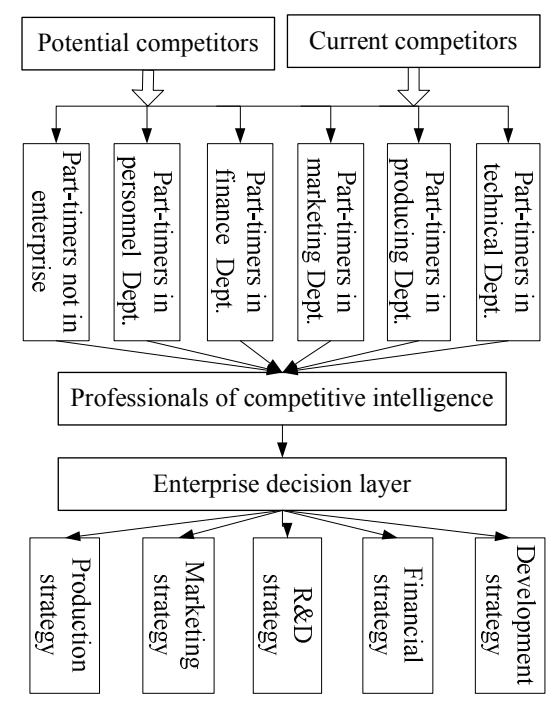

FIGURE2.WORKING NETWORK OF COMPETITIVE INTELLIGENCE

\section{B. Motivating Creative Power via Netizen Evaluation Collection}

Consumers, who master application skills of information technology and have access right to Internet, have more power in the consumption process. They not only begin to propose more personalized requirements about product, service, time, location and price which enterprise can offer, but also to express their opinion with a variety of network platform, to evaluate the quality of goods and services acquired.

Today, Internet has become main channel of information consumption, small and medium enterprises also begin to pay attention to their online reputation, i.e. how to be evaluated by consumers. Because no matter how, the reputation may be enlarged in geometric series on Internet. And the negative evaluation of someone consumer will engender enormous impact on the credibility of enterprise. When someone netizen compares superior product or inferior product, spreads own joy or evil, he/she also play a leading role.

As shown in Figure 3, in consumption life cycle of anyone commodity, someone consumer's spontaneous, uncontrolled evaluation will be an important information source of other consumers, and also have important influence in evaluation \& selection stage and purchase decision stage to other consumers deciding whether to buy. Therefore, it is very useful that consumer evaluation, opinions and suggestions are collected, sorted and mined to form consumer evaluation report. The report may not only be used as the reliable basis for enterprises devoting resources to ensure product quality, but also may become a driving force for enterprises making management innovation. According to consumer's suggestion, enterprises can improve product quality, adjust marketing strategy, and optimize management system. Enterprise is stimulated for 
innovation power to research new ideas, develop new products, and offer new services for meeting personalized needs.

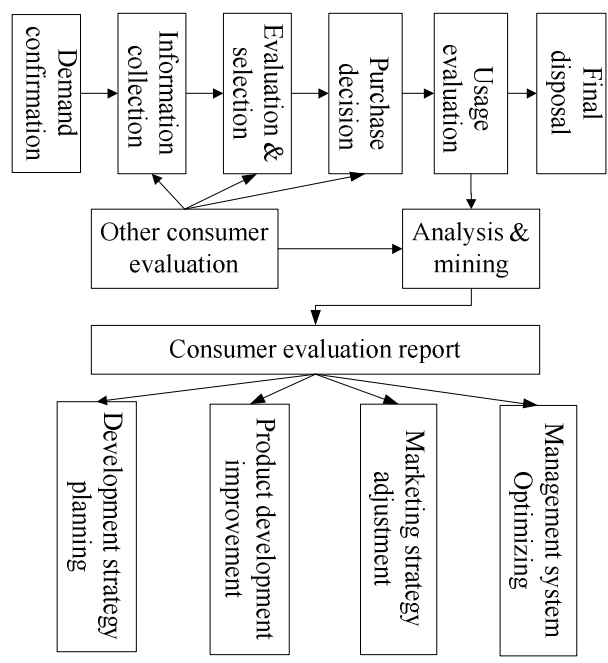

\section{FIGURE3.CONSUMPTION LIFE CYCLE AND CONSUMER} EVALUATION

The collection methods of consumer's evaluation, opinions and suggestions may be divided into two categories: explicit collection method and implicit collection method.

In recent years, there are more and more channels for consumers to express opinions and comments. Consumers can evaluate by e-mail, blog, BBS, online conversation, instant communication and etc. They can also evaluate with the help of special evaluation system provided by shopping website. Consumer's evaluation may be for purchased commodities, also may be for suppliers or manufacturing enterprises. And the evaluation may be a quantitative evaluation, also may be a qualitative description. Using "SuNing Yigou" as an example, consumer's evaluation includes consumer basic information and consumer evaluation information. The consumer basic information is consisting of registration name, shopping time, evaluating time, etc. The consumer evaluation information is consisting of comprehensive score, advantages, disadvantages, shopping experience, etc. "SuNing Yigou" website will offer consumer's satisfaction degree for a product which is expressed as a percentage. Clearly, this form of consumers' evaluation, opinions and suggestions for a commodity or manufacturer can be explicitly collected. The analysis result would be gained by manufacturers as decision-making reference.

In addition, even if consumers do not evaluate relevant commodities, but their activities and trajectories in cyberspace may be the tracking target of other consumers or enterprises. Consumers may shop online, may browse websites, news, advertisement, product descriptions or other network media resources, may upload their own audio or video, may express their views and proposals to someone kind of products, may release own DIY works. All these activities reflect consumer's preferences, interests and originality to a certain extent, will be grabbed by some business intelligence software with implicit collection method. Valuable information is finally found out, and is sent to enterprise as one of important references for decision-making.

\section{Changing Operation Mode through the Application of Information Technology}

With rapid development of computer network technology and communication technology, the application of information technology has penetrated into all social fields and economic fields, The manners and methods used by enterprises in business activities have changed fundamentally, a variety of new operation modes emerge as the times required. New format of industries are created, borrowed, and adopted by small and medium enterprises in their entrepreneurship process and development process.

Creative design operation mode: One of the most widespread definitions of creative industry is given by $U K$ $D C S M$ as "those activities which have their origin in individual creativity, skill and talent and which have the potential for wealth and job creation through the generation and exploitation of intellectual property" [5]. That is to say, creative industry is the industry which may convert new ideas into new products, and fit for following scopes: advertising, architecture, arts, crafts, design, fashion, film, software, music, performing arts, publishing, toy, game, radio and television, etc.

For example, many creative enterprises of textile and garment have moved into Foshan Creative Industry Park and Foshan New Media Industry Park. These enterprises use professional CAD software, endeavor to creative textile and garment design which are provided with high-quality, highgrade, and more fashionable. Production link is entrusted to more strength manufacturers, and with the aid of third party ecommerce platform to carry out marketing. The enterprise only insure quality monitoring in pre-production, production, afterproduction and after-sale service. Obviously, such kind of creative design operation mode may save a lot of money in production link and marketing link, so that enterprises can operate in start-up stage, under case of insufficient funds.

Personalized customization operation mode: Standardized mass production is often used by the enterprises of traditional operation mode as main means for responding to market competition. Such operation mode may lead to large inventory, slow capital turnover, and low additional value. In order to overcome drawbacks, enterprises must reform operation mode, make fusion of industrialization and informatization, innovate production technology. So the "personalized customization" flexible production technology may be adopted to meet personalized needs, consumers may also transform their role from passively accepting products to participating in products designing and manufacturing process.

For example, Foshan Weishang Furniture Manufacturing Co. Limited successfully explored a new way of upgrading traditional furniture industry through the close integration of information technology and manufacturing technology. Before sales, as long as customers give furniture type, style, color, size and other relevant requirements, professional designer can design according to their individual needs for free. 3D virtual furniture drawings can not only allows customers to see overall effect of custom-made furniture, but also can quick adjust according to new ideas, and the budget is finished immediately. 
Once customer order is confirmed, designer will make home field measurement in order to ensure accuracy of custom furniture. In the production process, order management system transfers design drawing to processing center for automatically splitting order and scheduling. Then manufacturing instructions are sent to digital production workshop. Customers can track order status via self inquiry system at any times. After sales, professional logistics company is responsible for door-to-door distribution, professional personnel is responsible for home installation and commissioning, as shown in Figure 4.

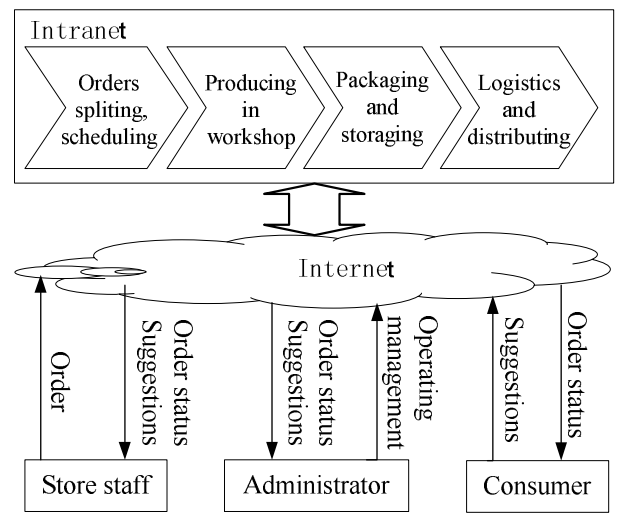

\section{FIGURE4.PERSONALIZED CUSTOMIZATION OPERATION MODE}

Foshan Weishang Furniture Manufacturing Co. Limited utilizes information technology in design link, production link, distribution link and service link. The production procedure is programmed. So production workers are greatly reduced, a large number of personnel turned to such services as receiving orders, design and installation. So Weishang Co. realized the transformation from traditional manufacturing industry to a modern manufacturing and servicing industry, promoted rapid growth of enterprises and development by leaps and bounds.

\section{Deciding Product Development by Means of Market Demand Mining}

Diapers and beers were put together to sell is a real case which occurred in America WAL-MART supermarket, and has been widely circulated among sellers. WAL-MART makes a lot of analysis and mining on a huge mass of original transaction data, and discovers that most commodities purchased with diapers are beers. So a behavior habit of Americans hiding behind "diapers and beers" is revealed, some young fathers often have to go to supermarket for buying baby diapers after work, and about $30 \%$ to $40 \%$ peoples will buy some beers for themselves at the same times. Obviously, if not using data mining technology, WAL-MART could not find such one rule.

In recent years, the domestic and foreign markets have become into changeable market from relatively stable market, its main features are: (1) Product life cycle shortened, product updates speeded; (2) Product variety increased, mass production quantity reduced; (3) Product quality, price and delivery period became three important factors of enterprises competitiveness [6].

Due to the diversity of consumer demands, the method, which may reduce production costs by mass production of single species, cannot work reasonably well. More and more enterprises begin to design and produce multi-variety and small batch products. Therefore, in order to survive and develop in the fierce market competition, modern enterprises must learn advanced business philosophy, making full use of data analysis technique and knowledge mining technique to mine consumer's demand information which is gathered from various channels, so as to determine enterprise business strategies. Under the guidance of analyzing and mining results, enterprises may improve product design, develop new product. And enterprise production may also be organized according to market demand for meeting diverse needs of consumers, as shown in Figure 5.

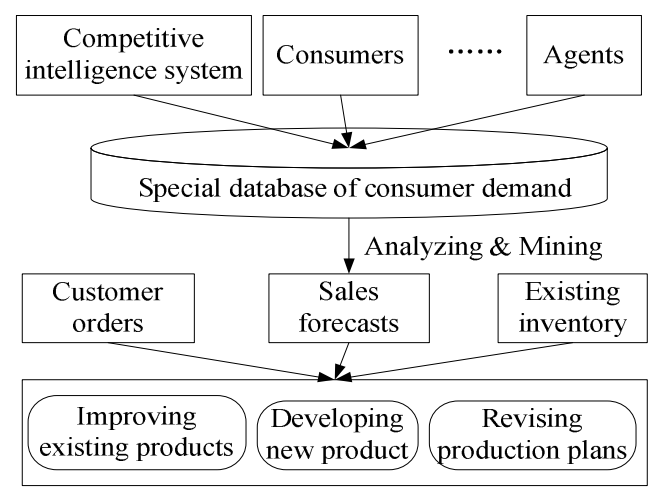

FIGURE5.ANALYSIS AND MINING OF CONSUMER DEMAND

Accurate market research is the premise and guarantee for enterprise to meet consumer demand. Primary data may be derived from the competitive intelligence system established by enterprise, or from consumer evaluation and opinion collected on network, or from distribution data provided by agents, or from original data offered by terminal sales, or from market survey report made by sales department or branches, etc. A wide range of raw data may construct a large scale of special database. Via scientific analysis and mining, the sales forecast report of enterprise products may be formed to guide product improving, products researching and enterprise manufacturing.

So-called new product do not mean to create a brand new product, the meaning of new concept exist only in consumer sense perception. No matter how innovative direction and how innovative degree the product is innovated, as long as product can meet new need of customers, it is a new product. The key problem is that enterprises should have ideas of continuous innovation. Enterprise product innovation may fulfilled from multi-dimensions, e.g. developing new products, increasing product functions, adjusting product elements, improving product performances, providing new services, etc.

\section{E. Bringing Products to Market with the Help of Network Marketing.}

In Jan. 2013, CNNIC (China Internet Network Information Center) released 31st Chinese Internet Statistics Development Report. The report shows that, at the end of 2012, the number of Chinese netizens reached 564 millions, Internet penetration rate is $42.1 \%$. With the popularization of Internet application and the improvement of network bank payment, shopping in the mall is no longer as only one shopping way, consumers 
may easily do shopping in self service mode. Or before purchase, consumers may get more consumption information from network channels; no longer simply rely on traditional media advertisement. Social and economic informatiztion environment had a significant impact on the original mode of enterprise operation and marketing. Network marketing has gradually been recognized by a vast number of small and medium enterprises, accepted and adopted.

Network marketing (On-line marketing or E-marketing) is based on Internet, a new marketing mode for achieving marketing goals by using digital information and network media. Its essence is that Internet is used as tracking platform in each service link of pre-sale, sale, after sale, including market research, customer segmentation, product development, sales strategy, feedback information, etc.

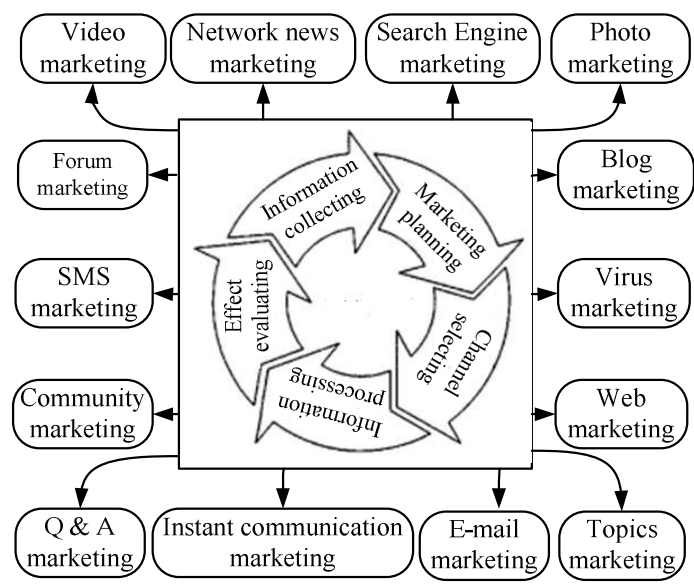

FIGURE6.NETWORK MARKETING

Network marketing is provided with many advantages compared to traditional marketing methods [7][8]: (1) The interactive nature of network marketing is helpful to realize the goal of whole process marketing. (2) Network marketing is benefit to reduce enterprise costs. (3) Network marketing can extend marketing scope of small and medium enterprises. (4) Network marketing can change competitive mode and enterprise image. Small and medium enterprises can propaganda enterprise culture and enterprise spirit via enterprise website and other online channels, quickly set up brand image in the minds of consumers, paving the way for enterprises to participate in market competition.

After small and medium enterprises formed a complete set of marketing ideas suitable to enterprise development, it is very important to set up effective marketing system, including internal and external information collection, network marketing planning, marketing channels selection, information processing, and information receiving evaluation etc. Network marketing channels, which may be selected by enterprise, include E-mail, website, virtual community, forum, micro-blog, instant communication tool, search engine, etc. as shown in Figure 6.
According to 31st Chinese Internet Statistics Development Report, at the end of 2012, , the proportion of marketing promotion on Internet is $23 \%$ among small and medium enterprises surveyed. In all kinds of marketing channels, Internet has already exceeded newspapers, magazines, TV, radio and other traditional media. And with diversified forms, relatively low limit, better promotion effect and other advantages, network marketing have become preferred channel of small and medium enterprise marketing. Therefore, network marketing will be adopted by more and more enterprises.

\section{CONCLUSION}

In today's information society and knowledge economy era, information technology develops rapid. The informatization construction would be used as main method which enterprises adapt to development of the times, meeting the requirements of informationalized consumers. In general, success or failure of enterprise informatization construction lies on informatization leadership of decision-making layers. Therefore, it is vitally important to enhance informatization leadership of decisionmaking layers. The informatization leadership includes the cognitive ability of informatization value, the regulation ability of informatization management and the evaluation ability of informatization performance, so that decision-making layers can exert influence on enterprise informatization work, letting informatization construction to meet enterprise's request, promoting informatization elements to play important role for supporting business innovation.

In addition, enterprises can also reform organizational structure, adjust department management responsibilities based on the application of information technology for adapting to the characteristics of today's information society.

\section{REFERENCES}

[1] Ye Zhou. Enterprise Marketing Model Innovation in the Informationization Environment. Marketing Managenment Review, No.1, 2011

[2] Jing-yan Wang, Zhen Zhu. Information Consumption and Informationalized Consumption. Journal of Foshan University (Social Science Edition), No.3, 2013

[3] Liang Yan. Strategic Thinking about Competitive Intelligence of Small and Medium-sized Enterprise. Sci-Tech Information Development \& Economy, No.17, 2007

[4] Zhen Zhu, Jing-yan Wang, Xiao-sheng Hu, Yan-chun Gu. Modeling and Analyzing of Informationalized Consumption Behavior. Proceedings of 2013 the 6th International Conference on Information Management, Innovation Management and Industrial Engineering (ICIII2013), Nov. 2013

[5] http://www.creativemetropoles.eu/uploads/files/cm_directory_of_ci_con cepts.pdf, Oct.10, 2013

[6] Cheng Jie, Song Fu-gen, Zhao Xiao-zhen. Shortcoming Analysis and Improvement for Production Planning and Control in MRP II . Industrial Engineering and Management, No.4,2006

[7] Yang Juan-li. Network Marketing Competitive Advantages of Small and Medium-sized Enterprise. Northern Economy and Trade, No.6, 2006

[8] Yang Zhi, Gao Hou-li. The Innovation Direction of Network Management and Distribution in Middle and Small Enterprise. East China Economic Management, No.10, 2004 